\title{
LICENÇA PARENTAL COMO AGENDA PARA A IGUALDADE DE GÊNERO: DIÁLOGOS ENTRE OS MODELOS SUECO E BRASILEIRO
}

\author{
PARENTAL LEAVE AS AGENDA TO GENDER EQUALITY: DIALOGUES BETWEEN \\ THE SWEDISH AND BRAZILIAN MODELS
}

\author{
Ana Carla Harmatiuk Matos* \\ Ligia Ziggiotti de Oliveira** \\ João Pedro Kostin Felipe de Natividade***
}

\begin{abstract}
RESUMO
Este trabalho examina o sistema de licença parental existente na Suécia como potencial promotor da igualdade de gênero para, então, versar sobre o sistema de licenças unilaterais existentes no Brasil. Utiliza-se o método comparado da equivalência funcional. Discutem-se as particularidades suecas para, em sequência, analisar o sistema brasileiro. Verifica-se, assim, a presença de grandes disparidades culturais e econômicas, além de outras, entre as duas nações, a desenharem cenários opostos na promoção da igualdade de gênero. Se o diálogo entre tais realidades não serve para transplantar experiências europeias às iniciativas latino-americanas, é possível, por outro lado, oxigenar a crítica de que o Brasil é carente de legislação a encorajar a persecução de iguais oportunidades e condições entre homens e mulheres, em indesejável estímulo a que as suas funções permaneçam vinculadas aos estereótipos dos papéis sexuais. De outra parte, as políticas públicas suecas, embora apresentem limitações, propõem-se, positivamente, a transformar esse tradicional paradigma.
\end{abstract}

\section{PALAVRAS-CHAVE}

Licença Parental. Gênero. Família.

\begin{abstract}
This article aims to examine the Swedish shared parental leave system as a potential way of promoting gender equality and, further, to analyze the Brazilian system of unilateral leave. To this end, the study adopts a comparative method of functional-equivalence, investigating Sweden's peculiarities and then the Brazilian establishment. Thus, it is verified the existence of great cultural and economic disparities between these two nations, and opposing backgrounds in the possibilities of gender equality promotion. If on the one hand it is not possible to simply transplant a European experience to the Latin-American context, on the other hand it is possible to enforce the criticism that Brazil

\footnotetext{
* Doutora e Mestra em Direito pela Universidade Federal do Paraná (2003). Mestra em Derecho Humano pela Universidad Internacional de Andalucía. Tuttora Diritto na Università di Pisa - Italia. Professora na graduação, mestrado e doutorado em Direito da Universidade Federal do Paraná. Vice-Coordenadora do Programa de Pós-graduação em Direito da Universidade Federal do Paraná. Diretora Regional Sul do Instituto Brasileiro de Direito de Família. Advogada com ênfase em Direito de Família (Curitiba, PR, Brasil).E-mail: a.c.matos@uol.com.br

** Doutoranda em Direitos Humanos e Democracia pelo Programa de Pós-Graduação da Universidade Federal do Paraná. Mestra em Direito das Relações Sociais pela mesma instituição. Professora de Direito Civil da graduação em Direito no Centro Universitário Autônomo do Brasil. Pesquisadora visitante do Instituto Max-Planck de Direito Comparado e Direito Internacional Privado em Hamburgo, Alemanha. Advogada (Curitiba, PR, Brasil).E-mail: ziggiotti@gmail.com

*** Graduando em Direito pela Universidade Federal do Paraná. Pesquisador no Núcleo de Estudo em Direito CivilConstitucional da UFPR (PPGD/UFPR). Pesquisador no Programa de Iniciação Científica da Universidade Federal do Paraná (PRPPG/UFPR). (Curitiba, PR, Brasil).E-mail: joao.pedronk@gmail.com
} 
lacks legislation to promote equal opportunities and conditions for men and women, in an undesirable stimulus to keep their functions linked to sex stereotypes. Therefore, the conclusions of this work are that Swedish policies, although encompassing several problems, advocate to positively change this paradigm.

\section{KEYWORDS}

Parental leave. Gender. Family.

\section{INTRODUÇÃO}

Diversas transformações materializaram-se nas últimas décadas no Brasil. Aumentou a participação feminina no mercado de trabalho, fortaleceram-se novos padrões familiares e o País industrializou-se. Por outro lado, o aparato legal e as políticas públicas brasileiras, pensados a partir de um modelo tradicional, em que o homem ocupa o lugar simbólico de provedor e a mulher o papel de cuidadora do lar, não assumem, ao nosso ver, papel suficientemente prospectivo para a efetiva promoção de igualdade de gênero. Tendências modernizantes percebidas em escala macroscópica nem sempre se refletem nas relações interpessoais mais cotidianas, tampouco oxigenam a contento o âmbito institucional ${ }^{1}$.

É de se enfatizar que o Estado tem assegurado, entre avanços e retrocessos, algum grau de proteção a novas configurações familiares ${ }^{2}$. Contudo, não assume a funcionalidade de estimular a modificação das convenções sociais de gênero em direção a uma sociedade materialmente igualitária.

A Suécia, por outro lado, é comumente lembrada por estimular a igualdade de gênero mediante políticas públicas. Uma delas corresponde à licença parental compartilhada, viabilizada pioneiramente em 1974 para substituir a então vigente licença-maternidade. O benefício consiste na oferta, a ambos os pais, de afastamento laboral remunerado quando do nascimento de uma criança.

Ao longo dos anos, várias reformas foram implementadas para dar efetividade a esse sistema, e até hoje problemas são enfrentados. Apesar disso, jamais se perdeu de vista um objetivo: promover a igualdade de gênero, tornando gradualmente possível, para homens e mulheres, a conjugação de trabalho e família (DUVANDER; FERRARINI; THALBERG, 2005).

Em oposição, no Brasil, nunca houve um sistema compartilhado de licença parental. O que há é a previsão constitucional e infraconstitucional de licença-maternidade (art. $7^{\circ}$, XVIII, CF) e de

\footnotetext{
${ }^{1}$ Sobre a primeira conclusão, confira-se: MARQUES; MELO (2008). Sobre a segunda, ainda: PINHEIRO; GALIZA; FONTOURA (2009, p. 853).

${ }^{2}$ A despeito do reconhecimento dos efeitos jurídicos, pelo Supremo Tribunal Federal, ainda em 2011, de uniões entre pessoas do mesmo sexo, emergem iniciativas legisladas em sentido contrário. Nesse sentido, ganha espaço no Congresso Nacional Brasileiro o Estatuto da Família (Projeto de Lei 6.583 de 2013) que visa a caracterizar como entidade familiar apenas as conjugalidades heterossexuais.
} 
licença-paternidade (art. $7^{\circ}$, XIX, CF; art. 10, $\S 1^{\circ}$, ADCT) - esta de cinco dias, a contar do nascimento. Recentemente avançou, com aprovação do Senado, projeto de extensão desse período para vinte dias - embora ainda em vista o atendimento da criança, e não da agenda de gênero.

Essa configuração, reproduzida de modo acrítico, mostra-se insuficiente para assegurar e promover a igualdade de gênero. A contrassenso, tem o efeito inverso, gerando disparidades no mercado de trabalho e desencorajando a contratação de mulheres, especialmente em idade fértil. Ademais, o vínculo entre recém-nascido e pai não é estimulado, o que obstaculiza o adequado desempenho da função afetiva pelo homem.

O presente artigo, a par desses institutos, objetiva questionar o modelo brasileiro levando em consideração especialmente a Suécia, considerando somente a realidade conjugal heterossexual ${ }^{3}$. Por primeiro, identificam-se as funcionalidades da licença parental no direito sueco para então questionar se as licenças maternidade e paternidade no direito brasileiro lhe seriam correspondentes, perfazendo microcomparação intercultural ${ }^{4}$.

Sem a pretensão de análise de direito comparado propriamente dito adota-se, para tanto, a vertente funcionalista do método da equivalência funcional. Isso porque o denominador comum entre os institutos é a funcionalidade, se considerada, a princípio, a necessidade de atendimento à criança 5 . Todavia, uma possível problematização na concepção brasileira significaria acrescer a motivação, já assumida no contexto sueco, de promover, por meio da licença parental, a efetiva igualdade de gênero.

Não se almeja proposição simplista de adotar experiências distantes como pretensos marcos de inspiração a uma realidade latino-americana. Diferentemente, o objetivo consiste em questionar o grau de (des)comprometimento institucional com a necessária reinvenção funcional da licença maternidade e paternidade, cujo potencial emancipatório parece, ainda, insuficientemente explorado.

\footnotetext{
${ }^{3}$ Embora se possa questionar o recorte em razão das novas realidades sexuais e afetivas, considera-se relevante a problemática proporcionada pela vivência de casais de sexos opostos, em resistência à disseminada noção de que tais relacionamentos já teriam alçado o status de horizontalidade, de igualdade e de solidariedade plenas. De todo modo, ao nosso ver, a aversão ao que se relaciona ao feminino perpassa, de algum modo, a discriminação em todos os casos.

${ }^{4} \mathrm{O}$ estudo volta-se à análise de um fragmento dos sistemas pesquisados, que, por possuírem diferenças sociais, econômicas e políticas diferentes, implicam comparação intercultural. Vide: SGARBOSSA; GEZIELA, 2008.

${ }^{5} \mathrm{O}$ funcionalismo epistemológico, representado por Cassirer, racionaliza esse objeto mediante empréstimo da matemática. Cunha-se a função 'axy', da qual se extrai 'a' como o problema; ' $x$ ' como a variável para os sistemas legais ‘ $\alpha 1, \alpha 2 \ldots$ '; e ‘y' como variável para as instituições legais ‘ $\beta 1, \beta 2 \ldots$... A função ‘a $\alpha 1 \beta 1$ ' corresponde à licença parental ( $\beta 1)$ introduzida pelo sistema jurídico sueco $(\alpha 1)$ para resolver a necessidade de atendimento ao recém-nascido (a). A fórmula 'a $\alpha 2 \beta 2$ ', por sua vez, representa a instituição ( $\beta 2)$ desenvolvida pelo sistema jurídico brasileiro $(\alpha 2)$ para solucionar o mesmo problema (a). Esse paralelo expande a análise comparada, direcionando-a não somente à comparação entre instituições, mas ao background de cada sistema, bem assim coloca elementos particulares em conexão e regularidade funcional. Vide: MICHAELS, 2006, p. 339-382.
} 


\section{POSSIBILIDADE E RELEVÂNCIA DO DIÁLOGO}

A mediação que se busca nessas reflexões não visa a promover a reprodução, no Brasil, de políticas públicas conformes os moldes suecos. Como já sublinhado, não se ignora a heterogeneidade social, econômica e política entre os dois países. Tampouco se recai em uma idealização eurocêntrica reprodutora de uma pretensa superioridade daquele continente. Porém, é possível reconhecer a presença de pontos tangenciais às duas realidades.

Quanto à economia, os indicadores brasileiros demonstram a presença de profundas fendas sociais. O Produto Interno Bruto (PIB) per capita é de \$ 11.604 (2014), a 60a posição mundial, e o Índice de Desenvolvimento Humano (IDH) perfaz 0,755 (2014), 75a, afora as desigualdades econômicas regionais, que acabam maquiadas por índices globalizantes.

A Suécia, por seu turno, segue a lógica dos países pós-industriais europeus, que experimentaram expressivo desenvolvimento econômico após o término da Segunda Guerra Mundial, produzindo “altos níveis de segurança existencial, manifestos na elevação dos níveis de renda, ampliação da expectativa de vida e outros indicadores” (RIBEIRO, 2007). O país apresenta PIB per capita de \$ 58.491 (2014), $7^{\circ}$ mais alto do mundo, IDH de 0,907 (2014), 14 ${ }^{\circ}$, e atende à tipologia de Welfare State social-democrata, regime que propicia garantias institucionalizadas contra os problemas sociais, tais quais desemprego e envelhecimento, idealizando-se uma "sociedade sem risco”, integralmente segurada (AHARONI, 1981).

A par desse panorama econômico, uma enganosa ideia nos leva a pressupor, por exemplo, que o mercado de trabalho sueco seria campo de iguais oportunidades e condições para homens e mulheres, superados os tradicionais standards de gênero.

Contudo, o mercado de trabalho sueco reproduz semelhante segregação ocupacional àquela verificada no Brasil. Na Suécia, as vagas nas áreas de saúde (enfermaria), cuidado pessoal, serviços domésticos e educação infantil são maciçamente preenchidas por mulheres, cerca de $80 \%{ }^{6}$. No Brasil, esse número é pouco superior: $85 \%{ }^{7}$. Do lado masculino, $80 \%$ dos postos na construção civil sueca são ocupados por homens, enquanto no Brasil esse número atinge elevados 97,2\%.

Isso demonstra que mesmo as mulheres participando ativamente do mercado de trabalho na Suécia, à taxa de ocupação de 83\% (2013), e no Brasil, 64,2\% (2012), atividades reprodutivas, historicamente reputadas femininas, são ainda exercidas majoritariamente por trabalhadoras.

Ademais, não há igualdade salarial entre homens e mulheres. Na Suécia, a remuneração feminina se equipara à masculina apenas em duas áreas - cuidados pessoais e educação infantil -

\footnotetext{
${ }^{6}$ Dados de 2012 (SUÉCIA, 2014).

${ }^{7}$ Dados de 2009 (BRASIL, 2011).
} 
mas, globalmente, há desigualdade. Em 1994, uma trabalhadora sueca recebia o equivalente a 84\% do salário masculino; em 2012, 86\% (SUÉCIA, 2014). No Brasil, em 2010, para as trabalhadoras formais, esse número era de 74,6\%; paras as informais, 63,2\%; e para as trabalhadoras com ensino superior completo, 59\% (BRASIL, 2011).

Por fim, o uso do tempo - horas gastas com trabalho produtivo e reprodutivo - é desequilibrado, em maior ou menor grau. Na Suécia, em uma semana, as mulheres destinam 30 horas ao trabalho produtivo e 26 horas ao trabalho reprodutivo; os homens, 37 horas e 21 horas, respectivamente, conforme dados de 2012 (SUÉCIA, 2014). No Brasil, o desequilíbrio é maior. As mulheres despendem 35,1 horas com trabalho produtivo e 20,8 horas com trabalho reprodutivo; os homens, 41,8 horas e 10 horas, nesta mesma ordem (BRASIL, 2015c). A mulher, nos dois casos, prepondera no desempenho de tarefas reprodutivas, mas no Brasil a diferença para o homem é superior a 10 horas.

Tais distanciamentos e proximidades não são paradoxos invencíveis. Antes, possibilitam que encontremos no alter a motivação para refletir sobre a nossa própria condição, encaminhando-nos ao reconhecimento de que múltiplas respostas podem ser adotadas - a depender das condições dos diversos cenários. Em conta essa premissa, o intento das ideias aqui lançadas é motivar o pensamento crítico e a construção de novos caminhos para a promoção da igualdade de gênero no Brasil, e não suscitar, necessária e simplesmente, o transplante de uma solução estrangeira.

\section{A LICENÇA PARENTAL INSERIDA NO SISTEMA SUECO COMO ESTÍMULO À IGUALDADE DE GÊNERO}

A Suécia obteve parcial êxito na transição normativa de um modelo unilateral para um modelo compartilhado de sustento familiar, em que as tarefas domésticas e atinentes ao crescimento e educação de uma criança são repartidas entre pai e mãe. Uma das razões dessa passagem é a inauguração da licença parental, compartilhada e remunerada, conjugada a fatores políticos e socioeconômicos.

O governo sueco, em 1974, para substituir a vigente licença-maternidade, instituiu sistema único de licença parental - afastamento laboral remunerado consistente, àquela época, no direito de pais e mães receberem do Estado valor equivalente a 80\% de seus salários por 180 dias para atenderem ao filho recém-nascido ${ }^{8}$.

\footnotetext{
${ }^{8} \mathrm{O}$ único requisito é que o afastamento laboral não ocorra simultaneamente, à exceção dos chamados double days (dias em dobro), período de 30 dias, no primeiro ano de vida do recém-nascido, em que pai e mãe podem usufruir da licença concomitantemente. A contabilização dos dias, nesse caso, dá-se em dobro.
} 
A política parece neutra do ponto de vista de gênero, pois dirigida indistintamente aos pais, cabendo-lhes decidir quanto à repartição da licença, embora apresente o escopo de estimular a participação igualitária no mercado de trabalho e na divisão das atividades domésticas, incluso o cuidado com a criança e as tarefas do lar ${ }^{9}$. Insuficiente para promover transformações relevantes, a estrutura desse sistema foi gradualmente expandida. Em 1976, aumentou-se a licença para 210 dias; em 1978, para 270, dos quais 30 remunerados à taxa mínima; e, em 1989, para 450, 90 remunerados à taxa mínima.

Essa expansão, no entanto, não teve reflexos significativos na adesão masculina ao benefício. No início da década de 90, os homens utilizavam, em média, 10\% dos 450 dias. Por isso, em 1995, o sistema foi novamente reformado, com a inédita estipulação de que um mês adicional deveria ser usufruído exclusivamente pelo pai e um pela mãe. Se um deles, por exemplo, decidisse não tirar a licença e seguisse trabalhando normal e ininterruptamente após o nascimento da criança, como penalidade, a família perderia o direito ao período extra. Em 2002, foi acrescido um novo mês a essa reserva, totalizando dois meses de uso exclusivo e intransferível, além de acrescentados mais 30 dias à licença, dilatando-a para 480 dias.

Para atender a anseios de pais com altos salários, que vislumbravam considerável redução de seus ganhos no caso de adesão à licença, em 2006 foi realizada nova reforma, elevando-se o teto do benefício. Dispõe-se, atualmente, de três níveis remuneratórios, auferidos à base diária (SVENSKT NÄRINGSLIV, 2014). O primeiro, nível auxílio-doença (sickness benefit level), calculado à equivalência de $80 \%$ do salário prévio, em 2014, remunerou até o limite de 1.216 SEK/dia ${ }^{10}$. Para estar apto a recebê-lo, é exigido que a pessoa tenha trabalhado consecutivamente nos 240 dias antecedentes ao nascimento da criança. O segundo, nível básico, define o benefício de pais com baixa ou nenhuma renda, e remunerou à taxa básica de 225 SEK/dia ${ }^{11}$. O terceiro, nível mínimo, aplica-se sempre aos 90 dias finais da licença, e remunerou à taxa mínima de 180 SEK/dia (CONFEDERATION OF SWEDISH ENTERPRISE INSURANCE, 2014).

Em termos concretos, a licença parental, hoje, prolonga-se por 480 dias, 390 remunerados ao nível auxílio-doença, cujo teto é 1.216 SEK/dia, ou à taxa básica de 225 SEK/dia, a depender do exercício de atividade laboral nos 240 dias antecedentes ao nascimento. Os demais 90 dias, para os dois casos, são remunerados à taxa mínima de 180 SEK/dia. Além disso, pai e mãe devem usar cada um, no mínimo, 60 dias da licença, sob pena de a família perder o intervalo adicional. Recentes

\footnotetext{
${ }^{9}$ Ressalte-se que a medida não era voltada somente a pais heterossexuais, mas também a pais homoafetivos. Visualizase esse ponto na neutralidade textual da legislação no que diz respeito a gênero.

${ }^{10}$ SEK corresponde à coroa sueca. 1.216 SEK equivalem a R\$ 507, conforme taxa cambial de 21/08/2015.

11225 SEK equivalem a R\$ 94; 180 SEK, referido na sequência, equivalem a R\$ 75.
} 
notícias dão conta, inclusive, do interesse de acrescentar-se mais um mês exclusivo, integralizando três meses-reserva (AGENCE FRANCE, 2015).

Todas as iniciativas descritas, entretanto, não podem ser concebidas dissociadas de suas reais funcionalidades, nem mesmo apartadas de outras políticas, igualmente vitais à maturação desse aparato. Evidentemente, a função de atendimento ao recém-nascido é inquestionável, mas um exame aprofundado demonstra que a licença parental resultou de ações empreendidas por grupos políticos feministas, sociais democratas e sindicatos - com objetivo de arquitetar a modificação de standards de gênero (HOBSON; FAHLÉN, 2011).

Tratou-se também, além de um reclamo político-social, de uma adequação necessária a mudanças sociodemográficas. No início da década de 70, a Suécia via-se defronte crescente número de divórcios, de 9.563 (1960) para 12.943 (1970); diminuição do número de casamentos, de 50.149 (1960) para 43.278 (1970); redução da taxa de fertilidade, de 2,17 (1960) para 1,94 (1970)12; e carência de trabalhadores no mercado de trabalho (BERGMAN; HOBSON, 2002). Diagnosticou-se que a causa de tais fenômenos seria, precisamente, a falta de políticas públicas direcionadas ao equilíbrio trabalho-família.

A licença parental, nesse sentido, instaurou nova faceta política: a busca por igualdade no núcleo familiar, mediante repartição mais equânime das tarefas domésticas e do cuidado com os filhos, e no mercado de trabalho, possibilitando à mulher disputar espaços profissionais em melhores condições. Uma série de medidas outras também foram adotadas, como altos investimentos em creches públicas, flexibilização das horas de trabalho e reorganização do sistema tributário.

O desenvolvimento de políticas dessa natureza, formalmente, retira das mães um injusto e pesado fardo: a necessidade de optar entre a criação de um filho e a vida profissional, como se fossem domínios excludentes entre si. Justamente por isso, políticas de ajuste do equilíbrio trabalho-família têm o condão de propiciar a homens e mulheres a congregação das duas esferas, possibilitando a democratização da órbita pública e privada (DUVANDER; LAPPEGARD; ANDERSON, 2010). A licença parental, portanto, deve ser interpretada como uma política pública adequada e necessária à igualdade de gênero, e não há como analisá-la dissociada desse enfoque.

Cada uma das iniciativas de aperfeiçoamento do sistema, nesse sentido, deve ser visualizada sob dois aspectos (CARLSON, 2013): a) de gênero - gender system approach, de Crompton (1999); e b) político-instrumental - identification of policy instruments, de Stone (2006). O primeiro centrase na reconstrução de padrões sociais, marcadamente, na tendência de remodelar as correspondências tradicionais entre homem-trabalho produtivo e mulher-trabalho reprodutivo; o segundo, por sua vez,

\footnotetext{
${ }^{12}$ Confira-se: SVERIGES OFFICIELLA STATISTIK (2015).
} 
preocupa-se com a maneira pela qual as políticas públicas produzem mudanças.

Na Suécia, são identificáveis três estratégias legislativas: o estabelecimento de sanções/incentivos, a concessão de direitos e a criação de regras. Essa ideia está presente em Duvander, Ferrarini e Thalberg (2005), para quem diferentes estruturas legislativas tendem a moldar as preferências, crenças e orientações pessoais, tendo em conta que o indivíduo faz escolhas racionais pautadas numa lógica de perdas e ganhos.

As sanções são consequências da observância ou inobservância de um comando normativo ou proibição, e dividem-se em negativas e positivas. As primeiras correspondem a um, por assim dizer, castigo, e, de maneira simplista, funcionam como uma reação má ao mal, portando natureza eminentemente repressiva. As segundas remetem a uma recompensa, e restituem o bem ao bem, dotadas, então, de carga promocional. Pode-se falar, assim, na produção de efeitos desagradáveis pela inobservância de certa norma, e, ao revés, agradáveis frente à obediência (BOBBIO, 2007). Quanto aos direitos, Stone qualifica-os como instrumentos mais sutis de mudança; e, às regras, como comportamentos normativamente prescritos em dadas situações.

Embora, do ponto de vista funcional, o direito seja recorrentemente visto como passivo - no sentido de apenas tutelar determinados interesses mediante a repressão das condutas desviantes -, o papel efetivado pelas sanções negativas deve ser repensado. O direito, no Estado constitucional, não se restringe à proteção de atos conformes às normas, mas adquire função promocional, no intuito de encorajar ações inovadoras. Dá-se vida a “uma técnica de estímulo e propulsão a atos considerados socialmente úteis, em lugar da repressão a atos considerados socialmente nocivos” (BOBBIO, 2007, p. 23-24).

Diante disso, a reforma que instituiu a licença parental intentava reconstruir as concepções de gênero no trabalho produtivo e reprodutivo, implementando liames entre os homens, suas responsabilidades domésticas e familiares, encorajando-os a democratizarem o tradicional papel de provedores do lar. Ao mesmo tempo, destinava-se a incentivar as mulheres a buscarem emprego anteriormente à licença, sob pena de serem remuneradas à taxa básica. Essa medida representou uma tática de incentivo, sanção positiva consistente em prêmio econômico, à inserção feminina no mercado de trabalho, pois o benefício corresponderia a percentual próximo à integralidade da remuneração ou à taxa básica, a depender unicamente da condição prévia de trabalhador(a) (CARLSON, 2013).

O estabelecimento dos meses-reserva, por sua vez, foi idealizado a fim de descolar as noções 
de parenting e childcare ${ }^{13}$ da órbita de atribuições relacionadas ao feminino. A reserva desse lapso, popularmente chamado “daddy quota”, tinha o propósito de fomentar o engajamento parental masculino e legitimar essa nova postura. Essa iniciativa ampliou um direito, mas sancionou sua inobservância com a perda dos meses-reserva.

Além dessa reestruturação, o teto do benefício foi elevado em 2006 no intuito de atrair pais com altos salários para o sistema. Alude-se a uma regra como tática político-instrumental, utilizada para desobstruir e incentivar a participação daquele setor social nas políticas de gênero.

Apesar de todos esses esforços, as estatísticas indicam que a adesão masculina à licença parental anda a passos lentos. Em 1980, os homens utilizaram 5\% dos dias; em 2000, 12\%; em 2005, 20\%; e, em 2013, 25\% (SUÉCIA, 2014). Observa-se vagarosa progressão no uso da licença, não necessariamente acompanhada da mudança postural esperada, em termos internos (pessoais) e externos (sociais).

Do ponto de vista interno, os homens tendem a assumir as atividades de cuidado da criança mais por gratificação individual do que para internalizar valores igualitários no compartilhamento de tarefas. Tanto é assim que tabus masculinos persistem, como os afazeres domésticos, majoritariamente exercidos por mulheres (ALMQVIST; DUVANDER, 2014).

De um lado, há tendência à ampliação do engajamento parental, propensão não espelhada no que tange à modificação dos papéis domésticos. A propósito, de 1990 a 2012 manteve-se estagnado o tempo médio gasto por homens nas tarefas reprodutivas - em geral, 21h/semana ${ }^{14}$. De outro, não se pode ignorar que diferentes modelos também são possíveis. Muitos pais não aderiram à licença parental formal, mas abraçaram práticas outras para auxiliar nas atribuições domésticas, como sair mais cedo do trabalho ou mesmo trabalhar diretamente de casa (HOBSON; FAHLÉN, 2011).

Do ponto de vista externo, em termos de mercado de trabalho, a sociedade reagiu timidamente às políticas de igualdade de gênero, pois perduram velhos estereótipos. O salário feminino equivale a $86 \%$ do masculino, e a estrutura ocupacional conserva segregação à base de tradicionais standards de gênero. Trabalhos relativos às áreas de cuidado, saúde e educação infantil são desempenhados, em $80 \%$ dos casos, por mulheres, o que naturaliza e perpetua falsa ligação entre trabalho reprodutor e sexo feminino ${ }^{15}$. Na seara política, diferentemente, houve ampliação da participação feminina. Em 1974, 20\% das cadeiras do Parlamento foram assumidas por mulheres,

\footnotetext{
${ }^{13}$ As duas expressões não encontram equivalentes na língua portuguesa. De todo modo, parenting representa as responsabilidade e atividades envolvidas no processo de criação de uma criança; childcare, por sua vez, diz respeito aos cuidados que devem ser tomados para/com a criança.

${ }_{14}$ As mulheres, em 1990, dispendiam 33h/semana com trabalho reprodutivo. Em 2012, esse número diminuiu para 26h/semana. Confira-se: SUÉCIA, 2014.

${ }^{15}$ SUÉCIA, 2014. Dados de 2012.
} 
enquanto em 2010 esse número chegou a 45\%.

A efetiva igualdade de gênero, para além de alterações legislativas, exige a internalização dos comportamentos desejados, a implicar choque de mentalidade micro e macrossistêmico e a substituição de valores tradicionais por prospectivos. A legislação é importante nesse processo, mas a lei, pura e simplesmente, não opera milagres. Em outras palavras, a transformação de um modelo normativo não significa a transformação do todo (YODANIS; LAUER, 2014, p. 63).

A igualdade de gênero plena é um sonho palpável, mas situado milhas distante, até para o sistema sueco. Parte do trajeto, todavia, já foi percorrido: o manejo político-legislativo para efetivála. A empreitada encontrou terreno fértil diante das condições socioeconômicas suecas da década de 70, que reclamavam o desenvolvimento de políticas de reestruturação do equilíbrio trabalho-família. Resta percorrer a outra parte: a assimilação da igualdade de gênero pela população, marcadamente masculina.

Ao contexto brasileiro, importa o comprometimento com o primeiro aspecto, assumido na conjuntura sueca: repensar as ferramentas tradicionais de atendimento ao recém-nascido com o pano de fundo da necessária redemocratização das esferas doméstica e laboral.

\section{AS LICENÇAS MATERNIDADE E PATERNIDADE EM CONTRASTE À LICENÇA PARENTAL}

No Brasil, as licenças maternidade e paternidade são os institutos funcionalmente equivalentes à licença parental sueca para garantir o atendimento às necessidades do recém-nascido. Não há previsão de licença compartilhada. Homens e mulheres têm direitos independentes em caso de nascimento ou adoção.

À mãe corresponde a licença maternidade, benefício previdenciário que consiste no afastamento laboral remunerado por 120 dias (art. $7^{\circ}$, XVIII, CF e art. 392 da CLT), passíveis de prorrogação por mais 60, a depender da adesão do empregador, se pessoa jurídica, ao programa Empresa Cidadã, consoante Lei 11.770/2008.

O salário-maternidade percebido durante o afastamento é equivalente à integralidade da remuneração da mãe contratada em vínculo empregatício. Se o salário for variável, o benefício corresponderá à média remuneratória dos seis últimos meses de trabalho (art. 72, Lei 8.213/1991 e art. 393, CLT). Ao contrário da Suécia, em que cabe ao Estado remunerar o(a) trabalhador(a) licenciado(a), é incumbência do(a) empregador(a) pagar o salário-maternidade, salvo no caso de adoção, guarda judicial e requerimento de empregada doméstica, contribuinte individual e facultativa, situações em que a obrigação será da Previdência Social. 
O pai, por seu turno, tem direito à licença-paternidade, afastamento laboral de cinco dias quando do nascimento do recém-nascido, sem prejuízo do salário. Trata-se de disposição do art. 10, $\S 1^{\circ}$, ADCT, que segue vigente, pois não promulgada a Lei a que se refere o art. 7, XIX, CF. À míngua dessa legislação, a licença paternidade segue aplicada conforme singela previsão do ADCT, limitada a cinco dias. Mesmo com o avanço do chamado Estatuto da Primeira Infância (PLC 14/2015), aprovado pelo Senado em 2016, com a previsão de extensão deste período para 20 dias, não se pode demarcar transformação paradigmática na concepção do regime de licenças.

Homens e mulheres não usufruem, afinal, de qualquer benefício compartilhado, como na Suécia. As licenças maternidade e paternidade, bem assim a legislação infraconstitucional brasileira, em geral, não privilegiam a repartição da parentalidade e das tarefas domésticas. Ao contrário, reproduzem estigmas de gênero, desencorajam mudanças posturais e reforçam a relação pai-provedor. Em termos outros, não tendem à igualdade.

Essa problemática não se circunscreve apenas a uma questão dos dias atuais, nem mesmo se apresenta como fator isolado. Além da questão de gênero, sexismo, racismo e condições de classe são imperativos que ainda acinzentam a sociedade brasileira, tendo superado, inclusive, o processo de redemocratização e abertura política enfrentado pelo País. Considere-se, por exemplo, que 80\% das mulheres pobres no Brasil são negras (BRASIL, 2015c). Revela-se, por certo, uma faceta mais concreta da vulnerabilidade no cenário pátrio, transpassada por marcadores variáveis e por imbricações complexas.

Ademais, não é excessiva a afirmação de que os rumos feministas europeus, em fluxos teóricos posteriores à década de 60, apresentaram-se bastante distintos das militâncias feministas nacionais, as quais, mesmo nos anos 70, ainda conduziam o debate da opressão de gênero sem descurar da agenda pela democracia, o que significou um contexto mais ambíguo e desafiador (COSTA, 2010).

De qualquer modo, é certo que grupos feministas pressionaram a produção da Constituição da República de 1988, o que convergiu, efetivamente, para a previsão de posições progressistas em matéria familiar e igualdade de gênero. Com efeito, à ocasião da derrocada do período militar, é ilustrativa da abertura de diálogos entre movimentos sociais e Estado a "Carta das Mulheres Brasileiras aos Constituintes”, preparada pelo Conselho Nacional dos Direitos das Mulheres, e da qual se aproveitaram $80 \%$ das pautas na redação do texto constitucional ${ }^{16}$.

Contudo, emancipar as vivências exige mais do que enunciar direitos. Além do texto normativo, necessário se faz que instrumentos legais adequados sejam implementados (VERRUCI;

\footnotetext{
${ }^{16}$ A propósito, confira-se: PITANGUY, 2002.
} 
PATAI, 1991). E, num contexto mais geral, é igualmente relevante ampliar a arena de vocalização dos anseios dos grupos vulneráveis. A real transformação social ocorre se os novos instrumentos estiverem acompanhados da fortificação do espaço de lutas sociais, pois acreditamos que direitos não são dados, mas sim, conquistados ${ }^{17}$.

É dever do Estado, por exemplo, a garantia de educação infantil “em creche e pré-escola, às crianças até 5 (cinco) anos de idade” (art. 208, IV, CF). Essa disposição, porém, não se vislumbra na realidade fática: mulheres com filhos pequenos encontram enorme dificuldade para deixar seus filhos em instituições de cuidado. Em 2012, no Brasil, 77,5\% das mães com mais de 16 anos não tinham nenhum de seus filhos matriculados nessas instituições (BRASIL, 2015c). Na Suécia, em 2013, ao contrário, 87\% das crianças de 1-5 anos estavam inscritas em algum tipo de instituição educacional (pre-school, leisure-time centres ou pedagogical care).

No Brasil, o insuficiente acesso às creches, somado à quantidade insatisfatória de mulheres em empregos formais capazes de resguardar condições mínimas à conciliação do trabalho e do cuidado com as crianças (SORJ; GAMA, 2014, p. 462), reforça a dicotomia das funções afetiva e econômica de acordo com perspectivas engessadas de gênero.

Tais dados, em acúmulo à ausência de reconhecimento registral paterno de aproximadamente 5,5 milhões de crianças no País, conforme constatou o Conselho Nacional de Justiça (BRASIL, 2015a), reporta à conclusão de que o modelo familiar brasileiro que mais sofre com a miséria compreende, precisamente, as famílias monoparentais compostas por mães sem cônjuges (SORJ; GAMA, 2014, p. 462).

Também a violência física de gênero revela intensa problemática. É conhecido o dever do Estado em assegurar “assistência à família na pessoa de cada um dos que a integram, criando mecanismos para coibir a violência no âmbito de suas relações” (art. 226, § 8º CF). Nesse sentido, em 2006, foi promulgada a Lei 11.340 (Lei Maria da Penha), para constranger e prevenir a violência doméstica e familiar contra a mulher.

Em 2014, a Central de Atendimento à Mulher, órgão vinculado à Secretaria de Políticas para as Mulheres, do Governo Federal, registrou 485.105 atendimentos. Desses, 52.957 referentes a relatos de violência contra a mulher - física (51,68\%), psicológica (31,81\%) e moral (9,68\%), principalmente. Desde a criação do serviço, em 2005, até 2014, já foram realizados 4.124.017 atendimentos (BRASIL, 2015b). E, ainda assim, o impacto da Lei Maria da Penha não foi sentido no

\footnotetext{
${ }^{17}$ Neste sentido, relevante a contribuição da Teoria Crítica dos Direitos Humanos. Dentre os autores, Joaquin Herrera Flores e David Sánchez Rubio figuram como importantes referenciais.
} 
número de feminicídios no País, a quase uma década da iniciativa ${ }^{18}$.

Em matéria trabalhista, de igual modo, poucas iniciativas apresentam-se, o que é ratificado pela estrutura das licenças vigentes no País. O ônus da parentalidade é entregue integralmente à mulher. Ao homem, é confiada a "missão" de seguir trabalhando, como se despido de qualquer engajamento parental - entendido como a "participação e a preocupação contínua do pai biológico ou adotivo no desenvolvimento físico, psicológico e social da criança” (FORGET, 2009).

A título exemplificativo, quanto ao exercício do cuidado materno e paterno-filial, de um plexo de mulheres casadas, trabalhadoras remuneradas e com filhos abaixo de 12 anos, 53\% entenderam não contar com responsabilização substancial dos companheiros, considerando, 64\% delas, mais decisiva a participação solidária de outras mulheres na criação das crianças - em especial, das avós (ÁVILA; FERREIRA, 2014, p. 25).

Revela-se, portanto, a reprodução de forte sistema patriarcal, apresentando ainda atualmente “contexto de opressão cujas engrenagens operam cotidianamente na intimidade das famílias e a partir do Estado” (MARQUES, 2015).

Destarte, as licenças maternidade e paternidade indicam a tipologia das parentalidades (QUÉNIART, 2002) presentes neste momento de transição. Concebe-se o homem como um pai protetor e provedor, ou ainda, um modelo mais mitigado, dito ambivalente. Assim, tudo que diz respeito à criança passa pela mãe e os papéis do pai referem-se ao exercício de autoridade e à iniciação a atividades reputadas masculinas. Ao pai, geralmente, cabe trabalhar, em ambiente externo, por longas horas, ao passo que a mãe deve concentrar redobrado esforço em casa, responsável pelo cuidado da criança e o trabalho doméstico. No segundo caso, o pai se situa entre representações paternais tradicionais e prospectivas. O homem nomeado ambivalente intervém no ambiente doméstico e familiar, no entanto, mais "prestando ajuda” do que assumindo verdadeira e autônoma responsabilidade.

A legislação e a estrutura do sistema de licença parental sueco, por outro lado, não se conformam às categorias de pais provedores e ambivalentes. Em verdade, visam ao desenvolvimento de pais para quem a relação com a criança é central, importante, aporta satisfação pessoal paternofilial e relacional. As tarefas domésticas e parentais são repartidas em vista da afinidade e disponibilidade de cada genitor, e não fundadas em predisposições de gênero.

\footnotetext{
${ }^{18}$ Por tal razão é que se estruturou o Observatório da Lei Maria da Penha no País: “The Observatory of the Maria da Penha Law is unique in that it focuses on implementation. As research members of the observatory, essentially we are trying to construct a monitoring methodology. This is a pioneering task, as Brazil is a country where there is a considerable distance between what happens at a legislative level and the law's actual implementation, a gap that affects women most” (AQUINO, 2013, p. 188).
} 
A licença parental sueca, então, foi pensada para promover, na órbita privada, o êxodo da categoria de pais provedores para esta nova categoria de pais, objetivando o compartilhamento de tarefas e o fortalecimento da igualdade de gênero. As licenças paternidade e maternidade no Brasil, diversamente, retratam o apego às tradicionais tipologias de pais provedores e ambivalentes, em incompatibilidade à previsão constitucional de isonomia entre homens e mulheres.

Parte desse contraste se deve, ao nosso ver, ao diferente modelo de Estado nos países comparados. A Suécia é classificada como um Welfare State socialdemocrata, conforme critério de Esping-Andersen (1991), pois atende a ideias de universalismo, igualdade social e descomodificação: todos os cidadãos têm acesso idêntico aos mesmos benefícios e podem optar, quando necessário, pelo afastamento laboral, sem que haja prejuízo de renda ou emprego.

O Brasil pode ser considerado (apesar de diferentes posicionamentos neste sentido) um Welfare State liberal porque direciona suas políticas públicas especialmente às classes menos favorecidas, em enfrentamento à questão da pobreza, o que institui estrutura social dual: cidadãos mais pobres necessitam dos benefícios estatais; os demais, dependem do mercado. Interessante o diagnóstico de que, em termos de políticas públicas, o passo concomitante ao combate à miséria deveria ser o da efetiva promoção da autonomia feminina (SORJ; GAMA, 2014). Todavia, parecenos que o contexto de crise econômica tem redesenhado o modelo estatal, aproximando-o do neoliberalismo avesso às políticas públicas que se consideram essenciais à redemocratização dos espaços sociais.

A Constituição de 1988, ao prever universalidade e isonomia, faz o Brasil rumar, ao menos formalmente, na direção dos Welfare States igualitários (BENEVIDES, 2011). Materialmente, entretanto, impõe-se óbice: de nada adianta a constitucionalização de direitos se não for acompanhada dos instrumentos legais adequados a implementá-los.

Conforme introduzido, porém, na atual conjuntura política brasileira, essa transição, em especial no que tange à promoção da igualdade de gênero pela via político-legislativa, quaisquer que sejam as propostas, enfrenta terreno inóspito. Os conservadores meandros do Congresso Nacional, em sua composição atual, reproduzem desigualdades e obstruem políticas voltadas à isonomia.

A legislatura 2015-2018 da Câmara dos Deputados acentua o fortalecimento das bancadas religiosa, ruralista, da segurança pública e empresarial, representativas de setores menos progressistas da sociedade e que juntas elegeram $417^{19}$ parlamentares nas eleições de 2014.

Com isso, oferece-se “à nação uma chance especial de se defrontar com seu histórico limite social causado pelo conflito entre o ideal de pluralidade e a moral majoritariamente conservadora,

\footnotetext{
${ }^{19} 81 \%$ do total de 513.
} 
por conseguinte, um conflito inerente à sua própria identidade” (BENEVIDES, 2011). Conclui-se, portanto, que se pode estar diante de verdadeira legislatura de retrocesso ao debate institucional de gênero.

Curiosamente, pouco se explora o argumento de que tal poderia ser um interessante caminho para a reinvenção das relações familiares contemporâneas, até de modo a preservá-las. Antes, a dependência econômica da esposa ao marido era um dos elementos indicados como necessários à estabilidade familiar. O forte ingresso das mulheres no mercado de trabalho desconstituiu esse vínculo em razão da germinal emancipação financeira feminina (OPPENHEIMER, 1994). Não alterou, porém, suficientemente os papéis familiares de homens e mulheres.

Essa disparidade, entre esferas pública e privada, cria instabilidade familiar, quiçá superável mediante repartição mais equânime das tarefas do lar e das responsabilidades parentais, capaz mesmo de reestabelecer a satisfação conjugal. Na Suécia, inclusive, comprovou-se que quando utilizam a licença parental por mais tempo, os casais são menos propensos ao divórcio (OLAH, 2001). Curiosamente, o benefício não é avesso, portanto, ao casamento, instituição valorada pelos setores sociais mais conservadores. Oferece, ao revés, possibilidades para reinventá-lo, com o objetivo de que se descole, enfim e aos poucos, das raízes sexistas em que historicamente se firmou.

\section{CONSIDERAÇÕES FINAIS}

A igualdade de gênero até hoje não foi alvo de suficiente estímulo no Brasil, seja na sociedade, na política ou na economia. Socialmente, a divisão de papéis familiares, parentais e domésticos mantém-se organizada conforme predisposições de gênero. Além disso, politicamente, parece, o contexto atual, pouco interessado na promoção da igualdade substancial, em razão da conjuntura de uma legislatura de possível retrocesso; e, economicamente, a participação feminina no mercado de trabalho, embora alta, segue cotidianamente desafiada por indicadores que anotam o desequilíbrio da trabalhadora em relação ao trabalhador, bem assim a reprodução de estereótipos tradicionais.

O estímulo da igualdade de gênero pela via político-legislativa, especialmente a introdução da licença parental compartilhada, representou a inauguração de interessante faceta no contexto sueco, a introduzir a agenda governamental às políticas de ajuste do equilíbrio trabalho-família. Como se viu, o background sociodemográfico e os reclamos de grupos organizados conduziram à concessão do benefício, bem assim à implementação de medidas outras, empregadas para criar um amplo sistema de incentivo à igualdade de gênero. 
Frise-se, então, que a licença parental não satisfaz exclusivamente a funcionalidade de atendimento ao recém-nascido, mas alinha-se à funcionalidade global de promover condições e oportunidades isonômicas a homens e mulheres bem como de alterar papéis historicamente enraizados.

A análise é relevante para que se promova exercício de autocrítica. No Brasil, as licenças maternidade e paternidade não assumem essa segunda e desejável feição. Ao revés, contribuem para a preservação de standards tradicionais condizentes com o materialismo social e o imperativo sexista ainda vigentes. O sistema brasileiro, em sua atual configuração, mostra-se insuficiente para fomentar alterações valorativas e inserir o homem à parentalidade e às tarefas domésticas.

Nesse ensejo, verifica-se que o Estado deve assumir papel de promotor de políticas de ajuste do equilíbrio trabalho-família, cabendo-lhe o manejo de instrumentos político-instrumentais com tal fito. Defende-se que a norma deve ser usada para modificar condutas no que diz respeito ao incentivo e concretização da igualdade substancial de gênero.

Por fim, destaca-se não se olvidar as evidentes disparidades sociais, econômicas e culturais entre as nações pesquisadas; portanto, não se acredita que a licença parental sueca deva ser pura e simplesmente transplantada à realidade brasileira. Objetiva-se, sobretudo, que a análise da outra nação alargue o horizonte da reflexão crítica brasileira na temática em prol de reais conquistas de gênero locais. Mesmo assim, embora as condições espaço-temporais suecas tenham sido amplamente favoráveis e necessárias à concessão da licença, nada impede que se viabilizem modelos desse porte em cenários diversos, como estimulante utopia. Nas palavras de Mario Quintana (1994, p. 94):

Se as coisas são inatingíveis... ora! Não é motivo para não querê-las... Que tristes os caminhos, se não fora

A mágica presença das estrelas!

\section{REFERÊNCIAS}

AGENCE FRANCE. Swedish fathers to get third month of paid paternity leave. Estocolmo, 2015. Disponível em: <https://goo.gl/jz65sN>. Acesso em: 14 nov. 2015.

AHARONI, Y. The no-risk society. New Jersey: Chatham House, 1981.

ALMQVIST, A.; DUVANDER, A. Changes in gender equality? Swedish fathers' parental leave, division of childcare and housework. Journal of Family Studies, v. 20, n. 1, abr. 2014. p. 19-27.

AQUINO, Silvia de. Organizing to monitor implementation of the Maria da Penha Law in Brazil. In: AL-SHARMANI, Mulki (Org.). Feminist activism, women's rights, and legal reform. London: Zed Book, 2013, p. 188. 
ÁVILA, Maria Bethânia; FERREIRA, Verônica. Trabalho produtivo e reprodutivo no cotidiano das mulheres brasileiras. In: ÁVILA, Maria Bethânia; FERREIRA, Verônica (Org.). Trabalho remunerado e trabalho doméstico no cotidiano das mulheres. Recife: SOS Corpo Instituto Feminista para a Democracia / Instituto Patrícia Galvão, 2014.

BENEVIDES, Cláudia do Valle. Um Estado de bem-estar social no Brasil? 2011. 98 f. Dissertação (Mestrado em Economia) - Programa de Pós-Graduação em Economia, Universidade Federal Fluminense, Niterói, 2011. Disponível em: <https:/goo.gl/g4b87u>. Acesso em: 16 ago. 2015.

BERGMAN, H.; HOBSON, B. Compulsory fatherhood: the coding of fatherhood in the Swedish Welfare State. In: HOBSON, B. Making men into fathers: men, masculinities and the social politics of fatherhood. Cambridge: Cambridge University Press, 2002.

BOBBIO, Norberto. Da estrutura à função: novos estudos de teoria do direito. Barueri: Manole, 2007.

BRASIL. Conselho Nacional de Justiça (CNJ). Programa Pai Presente completa cinco anos e se consolida no país. 07/08/2015. Brasília: CNJ, 2015a.

Presidência da República. Secretaria de Políticas para as Mulheres. Relatório Anual Socioeconômico da Mulher 2014. Brasília: Secretaria de Políticas para as Mulheres, 2015d. 181p.

Presidência da República. Secretaria Especial de Políticas para as Mulheres. Relatório Anual do Observatório Brasil da Igualdade de Gênero 2010/2011. Brasília: Secretaria de Políticas para as Mulheres, 2011, 65p. Dados de 2009.

. Secretaria Especial de Políticas para as Mulheres (SPM). Central de Atendimento à Mulher. Balanço 2014. Brasília: SPM, 2015b.

. Secretaria Especial de Políticas para as Mulheres. Relatório anual socioeconômico da mulher. Brasília: SPM, 2015c.

CARLSON, J. Sweden's Parental Leave Insurance: A Policy Analysis of Strategies to Increase Gender Equality. Journal of Sociology \& Social Welfare, v. 40, n. 2, jun. 2013. p. 63-76.

CONFEDERATION OF SWEDISH ENTERPRISE INSURANCE. Statutory and collective insurance schemes for the Swedish labour market 2014. 36. ed. Bromma: Arkitektkopia AB, 2014. Disponível em: <www.finfa.se>. Acesso em: 10 ago. 2015.

COSTA, Ana Alice Alcântara. O feminismo brasileiro em tempos de ditadura militar. In: PEDRO, Joana Maria; WOLFF, Cristina Scheibe (Org.). Gênero, feminismos e ditaduras no Cone Sul. Florianópolis: Editora Mulheres, 2010.

CROMPTON, R. Restructurating gender relations and employment: the decline of the male breadwinner. New York: Oxford University Press, 1999.

DUVANDER, Ann-Zofie; FERRARINI, T.; THALBERG, S. Swedish parental leave and gender equality: achievements and reforms challenges in a European perspective. Sweden: Institutet för Framtidsstudier, 2005. 
DUVANDER, Ann-Zofie; LAPPEGARD, Trude; ANDERSON, Gunnar. Family policy and fertility: father's and mother's use of parental leave and continued childbearing in Norway and Sweden. Journal of European Social Policy, v. 20, n. 1, 2010.

ESPING-ANDERSEN, Gosta. As três economias políticas do Welfare State. Lua Nova, São Paulo, n. 24, p. 85-116, set. 1991.

FORGET, G. La promotion de l'engagement paternel, des archétypes à transformer, une pratique à construire. In: DESLAURIERS, J.-M. (Dir.). Reflets: revue d'intervention sociale et communautaire, 2009, v. 15, n. 1, p. 79-101.

HOBSON, Barbara; FAHLÉN, Susanne. Parent's work-life balance: beyond responsibility and obligations to agency and capabilities. In: BRIDGEMAN, Jo; KEATING, Heather; LIND, Craig. Regulation family responsibilities. Farnham,UK: Ashgate, 2011. p. 21-46.

MARQUES, Stanley Souza. Ampliar a licença-paternidade para despatriarcalizar o Estado e a sociedade. Gênero e Direito, Paraíba, n. 1, 2015. p. 241-260.

MARQUES, Teresa Cristina de Novaes; MELO, Hildete Pereira de. Os direitos civis das mulheres casadas no Brasil entre 1916 e 1962 ou como são feitas as leis. In: Revista Estudos Feministas, Florianópolis, v. 16 (2), maio/agosto, 2008.

MICHAELS, R. The functional method of comparative law. In: REIMANN, M.; ZIMMERMANN, R. The Oxford Handbook of Comparative Law. New York: Oxford University Press, 2006. p. 339382.

OLÁH, Livia Sz. Gender and family stability: dissolution of the first parental union in Sweden and Hungary. Demographic Research, Rostock, v. 4, fev. 2001. Disponível em: $<$ https://goo.gl/LPM0PJ>. Acesso em: 15 ago. 2015.

OPPENHEIMER, Valerie Kincade. Women's rising employment and the future of the family in industrial societies. Population and Development Review, v. 20, n. 2, June 1994. p. 293-342.

PINHEIRO, Luana; GALIZA, Marcelo; FONTOURA, Natália. Novos arranjos familiares, velhas convenções sociais de gênero: a licença-parental como política pública para lidar com essas tensões. Revista Estudos Feministas. Florianópolis, 3, 851, 2009. p. 853.

PITANGUY, Jacqueline. Movimento de mulheres e política de gênero no Brasil. Novembro 2002. Disponível em: <https://goo.gl/lPdpVw>. Acesso em: 13 nov. 2014.

QUÉNIART, A. La paternité sous observation: des changements, des résistances mais aussi des incertitudes. In: DESCARRIES, F.; CORBEIL, Cristine. Espaces et temps de la maternité. Québec: Les Éditions du Remue-Ménage, 2002.

QUINTANA, Mário. 80 anos de poesia. São Paulo: Editora Globo S.A., 1994.

RIBEIRO, Ednaldo. A consistência das medidas de pós-materialismo: testando a validade dos índices propostos por R. Inglehart no contexto brasileiro. Sociedade e Estado, Brasília, v. 22, n. 2, p. 371400, maio/ago. 2007. 
SGARBOSSA, L. F.; GEZIELA, J. Elementos de direito comparado: ciência, política legislativa, integração e prática judiciária. Porto Alegre: Sérgio Fabris Editor, 2008.

SORJ, Bila; GAMA, Andréa. Family policies in Brazil. In: ROBILA, Mihaela (Org.). Handbook of family policies across the globe. New York: Springer, 2014. p. 459-471.

STONE, D. Policy paradox: the art of political decision-making. New York: Norton, 2006.

SUÉCIA. Statistics Sweden. Women and men in Sweden 2014. 3 jul. 2014.

SVENSKT NÄRINGSLIV. Statutory and collective insurance schemes for the Swedish labour market 2014. 36. ed. Stockholm: Svenskt Näringsliv, 2014.

SVERIGES OFFICIELLA STATISTIK. Summary of Population Statistics 1960-2014. 19 fev. 2015. Disponível em: <http://www.scb.se/sos>. Acesso em: 10 ago. 2015.

VERRUCI, Florisa; PATAI, Daphne. Women and the new Brazilian Constitution. Feminist studies, v. 17, n. 3, 1991. p. 550-568.

YODANIS, Carrie; LAUER, Sean. Is marriage individualized? What couples actually do. Journal of family theory and review, Malden, v. 6, n. 2, p. 184-197, June 2014, p. 63.

\title{
PARENTAL LEAVE AS AGENDA TO GENDER EQUALITY: DIALOGUES BETWEEN THE SWEDISH AND BRAZILIAN MODELS
}

\begin{abstract}
This article aims to examine the Swedish shared parental leave system as a potential way of promoting gender equality and, further, to analyze the Brazilian system of unilateral leave. To this end, the study adopts a comparative method of functional-equivalence, investigating Sweden's peculiarities and then the Brazilian establishment. Thus, it is verified the existence of great cultural and economic disparities between these two nations, and opposing backgrounds in the possibilities of gender equality promotion. If on the one hand it is not possible to simply transplant a European experience to the Latin-American context, on the other hand it is possible to enforce the criticism that Brazil lacks legislation to promote equal opportunities and conditions for men and women, in an undesirable stimulus to keep their functions linked to sex stereotypes. Therefore, the conclusions of this work are that Swedish policies, although encompassing several problems, advocate to positively change this paradigm.
\end{abstract}

\section{KEYWORDS}

Parental leave. Gender. Family. 